essential because the motivation is not risk of collision but the original relative bearing and the closing range. The overtaking ship cannot avoid this responsibility whatever the other ship does. But if the ship being overtaken invokes Rule $17(\mathrm{a})(\mathrm{ii})$ and, therefore, $8(\mathrm{~d})$, are both equally responsible?

Rules 17(a), (b) and (d) apply as much to Overtaking cases as to crossing but the safety restriction in $I 7$ (c) does not. I find that I am by no means alone in thinking that unadvertised wandering by a ship being overtaken is far more embarrassing and dangerous than similar behaviour by a stand-on ship in a crossing situation. This is particularly so in heavy weather (Nassau-Brott collision) and in constricted waters. The complete freedom given to the stand-on ship in the Overtaking case is thought to be highly dangerous, while the concurrent application of Rules $I_{3}(d)$ and 8 (d) is equivocal to say the least.

Rule 19. Rule 19 (a) is a peculiarly worded statement. Rule $19(b)$ applies obviously in varying degrees of visibility and must include circumstances of less than good visibility in which ships can still see other ships. Rule 19(c) applies similarly whether or not the vessels are in sight of others. Rule 19 (a) as worded does apply to Rules 19 (d) and (e). As the requirements of Rules I 9(b) and (c) are amply covered by Section I, the matter could be rectified by omitting them from Rule i 9 . Alternatively i 9 (a) could be omitted.

Rule $19(d)$. Although the practice of cross-referencing in Rules of this kind should be avoided (19(c) is quite unnecessary), the heavy responsibilities involved in Rule 8 might well be drawn attention to in $19(\mathrm{~d})$.

Rule 19(e). It seems that, hidden away here, is that well known and dangerous assumption of identity between a fog signal and a radar echo. No positive solution to that problem has yet been reached. There is also the implication in 19 (e) that a close-quarter situation between two ships under way in fog can exist without any danger of collision. This possibility seems to be so remote as to be hardly worth writing into a Rule.

Apart from the above commentary on the 1972 Regulations, Parts A and B, it may be of interest to compare the Steering Rules as a whole with the 1960 Rules. They have been summarized in Tables I and II, and this enables the complexity and the contribution to safety of the two sets of Rules to be compared. He would be a brave man who would say that sufficient manouvring guidance is given in the new Rules to balance the undoubtedly great increase in freedom to manœuvre or that the new balance is an improvement on the old.

\title{
A Voyage Towards the South Pole
}

Dr. David Lewis, a Fellow of this Institute and occasional contributor to the Journal, arrived at Palmer Station in the Antarctic, under jury rig, on 29 January having left Sydney on 20 October 1972 and stopped twenty-four hours at Stewart Island, N.Z., on the way. His long-term objective is to circumnavigate the Antarctic Continent, single-handed. He was twice capsized, in the course of which his gloves disappeared which resulted in badly frost-bitten fingers. After two months day and night in insulated boots, the warmth in the U.S. base when he arrived made his feet balloon and crack.

In a letter dated 12 February and addressed jointly to three friends ('onefinger typing is all my frost-bitten but healing fingers will allow . . .'), amongst whom the Executive Secretary, he explains some of the circumstances of his 
voyage and gives extracts from the ship's log. It is not clear from the letter what Lewis's new boat is, although he encloses a photograph taken on arrival. Isbjorn, the boat in which he intended to effect the circumnavigation, was apparently sunk in the Pacific earlier on, in what circumstances it is not clear. It was in Isbjorn that Dr. Lewis carried out an investigation sponsored by the Australian National University into Pacific native navigation and land-finding techniques, a truly remarkable work described in $W e$, the Navigators which is reviewed by Admiral Ritchie on p. 393.

Some extracts from the letter and the log are given below.

\section{FROM THE LETTER}

Left Sydney seen off by barquentine New Endeavour \&c. about 20 Oct. 72. Half Moon Bay Stewart Island N.Z. for a day and a night leaving I Nov. Wonderful place and people-lobster fishermen and helicopter meat (deer) hunters. Sailed S.E. to $60 \mathrm{~S}$. where inside drips froze and decks often snow covered. Some bad gales. Frost-bite of hands was in the hours of bailing out and clearing wreckage after the capsize (29 Nov.) - couldn't find gloves. My feet were o.k. till got here, but after two months in insulated boots day and night without ever taking them off the warmth of the U.S. base made them balloon and crack-only now able to walk properly. All fingers intact except nails which may not re-form. Jury mast was first spinnaker pole ( $1 \circ \mathrm{ft}$.) which progressively crumbled and

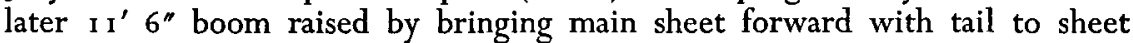

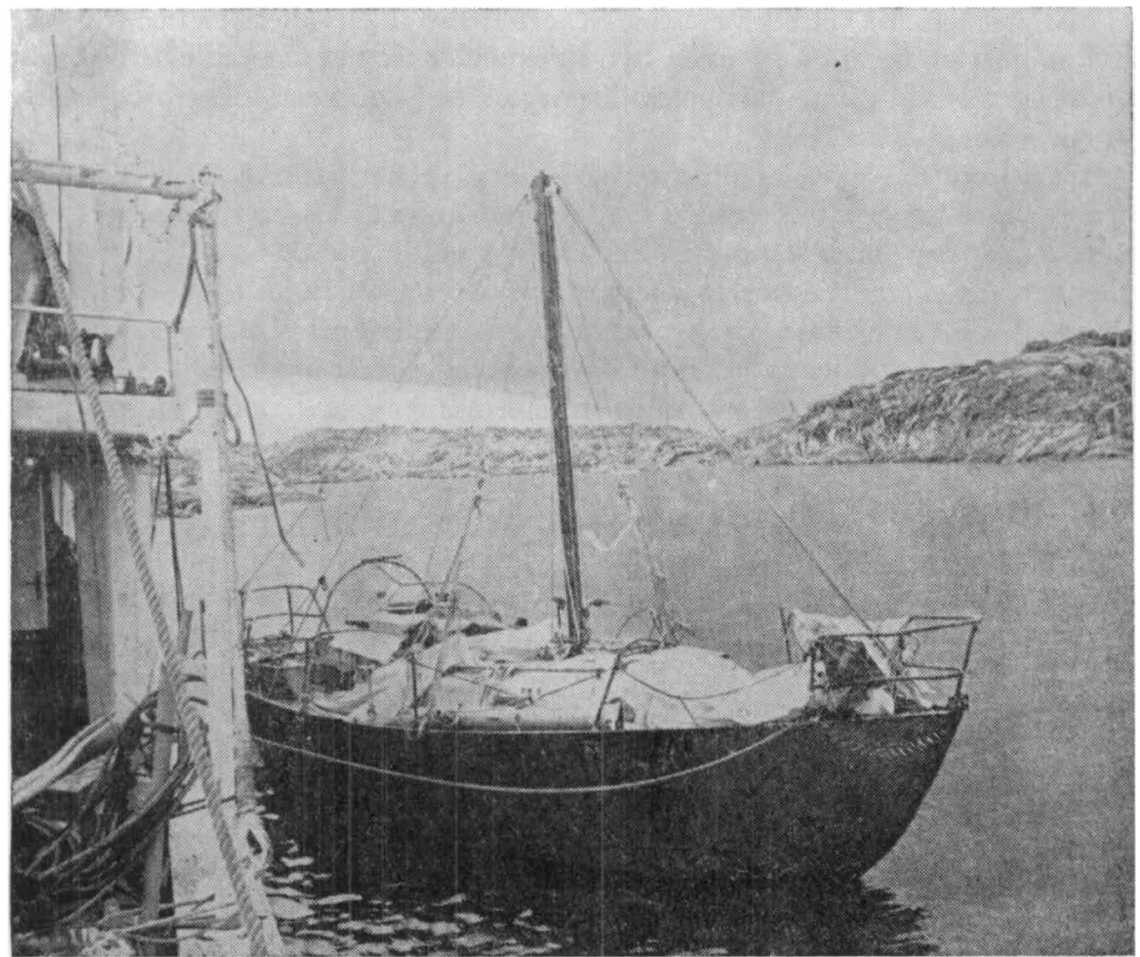

FIG. I. Moored alongside Calypso in Palmer lsland 
winch and having steadying side shrouds. Split staysail along centre seam to allow it to set and carried storm tri-sail. Progress then much better averaging something like $40 \mathrm{~m}$.p.d. kept between $60-62 \mathrm{~S}$. for westerlies to $65^{\circ} \mathrm{W}$. then headed south for Anvers Is. Sighted it in gale. Deck watch despite lack RO time signals 2 months only 55 secs out. As gale eased magnificent panorama of Graham Land mountains, icebergs, skerries. Took 3 days to Palmer beating against light winds and lying to for one $60 \mathrm{kt}$. blow. Narrow escapes as dozed among skerries and bergs. The last night tacked through sleet, brash ice, one area breakers over shoal, drinking rum at frequent intervals to keep warm. Entered harbour first light 29 Jan. tying up alongside Cousteau's Calypso, 60 days since accident. I forgot to mention that two weeks after first capsize was turned over once more with less damage-except to my nerves and the steel frame over main hatch which was bent in.

Helpfulness of all at this very busy station has been wonderful. We are building a mast from timber here, I am making a new self steering gear as the other was smashed and I think we can get motor, radio, \&c. to work again. Have mended the torn sails now. Will rig gunter with short, stout mast. This place is gloriouspenguin rookeries, skuas, weddell, elephant and leopard seals. The station is on a kind of moraine backed by ice cliffs and rising piedmont.

\section{FROM THE LOG}

[D.L. indicates a subsequent annotation by the author]

$Z+9$ Wednesday 29 November. End of 6 th week out. About 02.00 , first light. Turned over (complete $360^{\circ}$ capsize) to starboard and ahead. Fore mast broke 7 feet above deck and went over to starboard. Fore hatch sprung but can be approximately closed. Stbd. side $b^{\prime \prime}$ steel coachroof all dented in and split 4" alongside one window. I ft. water over floorboards. Glass beginning to rise. Gale southerly now I think. About 08.30. Had baled over floorboards when knock down to port. Flooded again and lost Beaufort. Since then cold front gale and glass rising. Too tired to be concerned.

1 2.00 (above written now). 980, moderating force 10-9.

Heavy seas breaking against us. Everything soaked and destroyed. Must rest a little.

19.30. Est. position 60.04 S., 136.30 W. (yesterday's).

Est. ran $40 \mathrm{M}$. in rest of yesterday (making accident $135.35 \mathrm{~W}$.).

D.W. was 4.21 fast yesterday. Est +6 , i.e. 4.27 fast today. Crack coachroof gives leak stbd. hull-small. Baled out twice, cleared cockpit drain and organized. Cleared up below. Mast broke $5 \mathrm{ft}$. (7, D.L.) above deck. Am retaining bottom. Rest now (after freeing eye splices from rigging screws, D.L.) only attached on starboard shroud and backstay. S. steering completely out, cogwheels missing. Everything-charts, books, \&c. soaked. D.W. is o.k. Hands bleeding and very numb. Will try the fur clothing as if all goes well have to steer soon. Fine with high glass. Will have stiff drink and try to sleep. Sleeping bag soaked.

Friday I December. 12.30. Westerly 6-7, snowing. Cleared mast, sails, wreckage from deck. Hands eased a little held against tummy all night. No light or heat yet. First (cold) meal. Wet gloves working outside àre big help.

18.00. First hot meal-stew and coffee. Lashed down stove (\&c.). Deck cleared ready to attempt jury mast. Near gale, top 6 and 7 with gusts ever since accident. Usually $-2^{\circ} \mathrm{C}$. Snowing a lot today, fine now.

21 .00 Rigged halyds on spinnaker pole. Fourteen more buckets water from bilge. 
Est. D.W. 4.39 fast $(+6)$. Another coffee-this must be Christmas!

Thursday 7 December. $Z+9$ becomes $Z+8$ from noon.

03.00 W. 5-6. Spent one hour unravelling spars on deck. Hands-always pain. 08.00. Glass still rising sun $\odot$ taken. Position line (approx. long D.L.) 34 M.P.D. Jury rig!

Noon. Mast up. Underway headsail-what a cat's cradle. Wild motion and squalor everywhere these days. Effort to retain manhood and behave like one (a man). A shutter has closed between a week ago when I was part of the living and since. Chance (of survival D.L.) negligible but effort in spite pain and discomfort. These last are very great. Must go on striving to survive as befits a man. Doing my sorry best. Susie and Vicky without a daddy is worst of all. $\odot$ taken. 15.00. Bailed 15 buckets. West $\mathrm{I}-0$, sunny, $+4^{\circ} \mathrm{C}$ ! Hoisted storm trisail. Position 60.5 1 S., 128.04 W. 34 M.P.D. since jury rig. Nat. geog. furthest from land any place except that am about $900 \mathrm{~m}$. nearer Antarctica. N.B. Noted this also on 10.12 .72 at 124 . I0.

Est. D.W. 5.25 fast (gain 6).

20.00 E.N.E. blowing up. Glass falling fast. $8 / 8$.

23.30 E. force 7. Snowing. Lowered trisail. Being set west of south.

Time $Z+8$. Friday 8 December. 04.00. S.E. force 7 , snowing heavily, 962 . Gybed to stbd. Pointing east of north. (near hove-to). 06.30. Knock over. Moving north 2 knots. 13.30 Moving N.E. Gale. Southerly, glass rising, thin overcast. Rough night. Surprising no fear at almost certainly having to die, a lot of disappointment though letting down Susie and Vicky through years when they would need me. Est. D.W. $5 \cdot 3^{1}$ fast (gain 6).

$Z+8$. Saturday 9 December. 07.00. S.6, glass 983 .

10.00. 24 buckets bailed out. Sail (jib) which had partly lowered with foul halyard and was aback during gale, hoisted. Moving well. Snow showers. Good visibility. Cold coffee.

p.m. Earning membership of humanity-must earn it every day to be a man. O.K. today so far after this morning. There seems hope of hands healingexcept finger tips-would transform what could do.

18.00. Light S.W. Hoisted tri-sail. Motor, can't start, anti-rust applied.

20.00 N.W. light increasing. Glass falling. Gybed to port gybed heading north of east.

D.W. $5 \cdot 37$ fast (gain 6).

$\mathrm{Z}+8$ TO. Monday 25 December-Christmas Day. $\mathrm{Z}+7$ at noon.

$05.00 \mathrm{~S}$.W. light, squally, $7 / 8$ snow showers, livid leaden sea and sky. $987 \frac{1}{2} \mathrm{mb}$, $-2^{\circ} \mathrm{C}$.

10.30. $986 \frac{1}{2}, \mathrm{XX}+1^{\circ} \mathrm{C}$. More Christmas biscuits for ice birds. Attempting to dry sodden charts? Hopeless. Sugar in plastic bags had all dissolved.

1r.20. $\odot$ taken. Muesli, tin peas, $\frac{1}{2}$ tin corned beef, sweets, chocolate.

15.40. $\odot$ taken. S.W. 6, snowing squalls, 987-, steep waves. swell from west, rough so movement about boat very difficult. Drying some charts and socks but everything wet, tool locker contains water, mattresses wet inside and all. I 8.00. Z+7. $987+$, S.W.6, 5/8 steep swells.

20.00. Hand steering with yoke lines. W.S.W. 6 becoming 7. Sleeping bags, \&c. wet. Spray and snow showers. Position: $61^{\circ} .30^{\prime}$ s Poor $\odot$, 104.57' W. Since last $\odot$ on 15 Dec. averaging 45 M.P.D. Great improvement new mast 
and sail. If only these figures are correct is best Christmas present. Est. D.W. 7. 13 Fast.

\section{A Visit to Japan}

At the invitation of the Nautical Society of Japan, a society with aims similar to the Institute's, the Executive Secretary visited Japan between 5 and 17 April. A short report to Council follows.

I. Members of the Nautical Society of Japan (N.S.J.), most of them professors at the University of Mercantile Marine at either Tokyo or Kobe, have from time to time visited this country and the Institute has generally been able to smooth their paths. No doubt this has played its part in such collaboration as there has been between the two bodies, including the publication over the years of a substantial number of Japanese papers. The present visit was arranged through the intermediary of Professor Nishiyama who has been working at the University of Wales Institute of Science and Technology. The object of the visit was to further cooperation between the two bodies by getting to know the people concerned and to see some of the work now going on in Japan, particularly in fields where this Institute has been prominent, such as traffic routing \&c. When a visit had been agreed in principle, a schedule was proposed and the President then informed the President of the N.S.J. that the visit was an official one made on the Council's behalf.

2. It was clear from the start that the Institute was held in very high regard in Japan and that the visit was going to be treated as something of an event. On the evening of my arrival ( 5 April) there was an official reception at the Japan Marine Club attended by representatives of the following organizations:

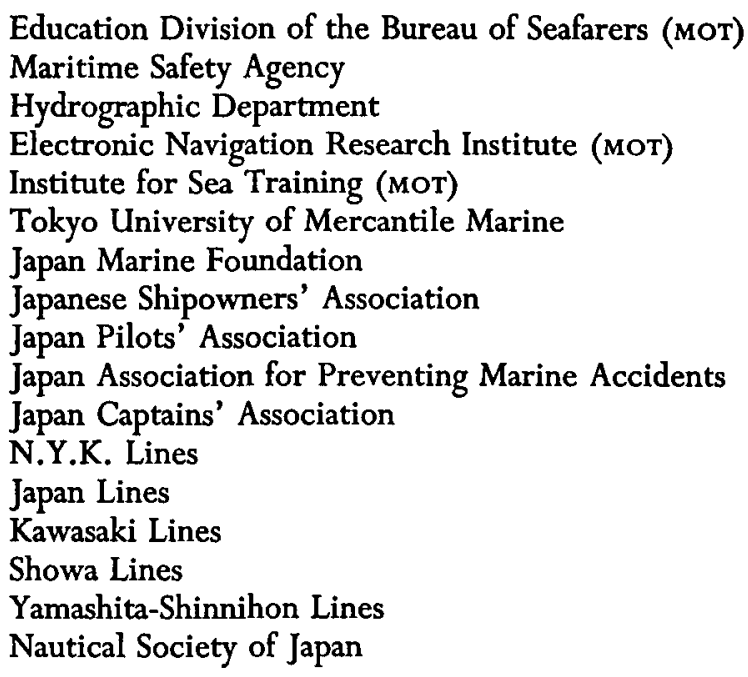

I was to see many of the representatives, most of whom were at director level, again, and after some formal words of welcome and response, followed by a 